\title{
Studies on Physical Properties of Peanut Seed
}

\section{DK Gojiya ${ }^{1 *}$, UD Dobariya ${ }^{2}$, PA Pandya ${ }^{3}$ and KM Gojiya ${ }^{4}$}

${ }^{1}$ Assistant Research Scientist, Junagadh Agricultural University, Junagadh, India

${ }^{2}$ Scientist (Agril. Engg.), Sardarkrushinagar Dantiwada Agricultural University,

Dantiwada, India

${ }^{3}$ T.O. to Hon'ble Vice chancellor and Assistant Professor, Junagadh Agricultural

University, Junagadh, India

${ }^{4}$ Ph.D. Scholar, Junagadh Agricultural University, Junagadh, India

*Corresponding Author: DK Gojiya, Assistant Research Scientist, Junagadh

Agricultural University, Junagadh, India.

DOI: 10.31080/ASAG.2020.04.0814
Received: January 22, 2020

Published: February 26, 2020

(c) All rights are reserved by DK Gojiya.,

et al.

\begin{abstract}
Physical and mechanical properties of peanut kernels are important to the researcher, design engineer, the food industry. The present study aimed to determine and recognize a database of physical and engineering properties of peanut seed which play an important role in designing and developing of specific machines and their operations such as planting, harvesting and grading. The physical properties namely Moisture content, \% (w.b), Length (mm), Width (mm), Thickness (mm), Shape, Sphericity (mm), 100 kernels weight $(\mathrm{mm})$, Geometric mean diameter (mm), Surface area $\left(\mathrm{mm}^{2}\right)$, Aspect ratio (\%), True density (kg/m3), to know Bulk density $\left(\mathrm{kg} / \mathrm{m}^{3}\right)$, Porosity (\%), Angle of repose, degree, Terminal velocity $(\mathrm{m} / \mathrm{s})$, Coefficient of friction (Wood, Glass and GI surface) and Germination percentage (\%) of peanuts variety kernel GG-20 and TG-37A were investigate and reported in this study. Size distribution of GG-20 and TG-37A peanut kernels also studied.
\end{abstract}

Keywords: Peanut; Physical Property; GG-20, TG-37A; Equipment Design

\section{Introduction}

Peanut (Arachis hypogaea L.) is an important crop globally as well as in our country belonging to family Leguminosae [1]. Thorough understanding of the physical properties of peanut kernels is helpful to improve the technology associated with operations and equipment related to post-harvest processes such as cleaning, sorting, transport, ventilation, drying, and storage. Physical and mechanical properties of peanut kernels s are important to the researcher, design engineer, the food industry and the consumer alike. The question of shape and size is also important in problems of stress distribution in the material under load and in development of sizing and grading machinery.

Knowledge on density and specific gravity of agricultural products is needed in calculating thermal diffusivity in heat transfer problems, in separating the product from undesirable materials and in predicting physical structure and chemical composition. The data on static and sliding coefficient of friction for fruits are needed by design engineer for rational design of handling and storage systems. Mechanical harvesting, bulk handling, transportations and storage of fruits and vegetable products have also indicated a need for basic information on mechanical properties.

For an adequate design of the equipment involved in peanut kernels post-harvest, it is essential to have a clear knowledge of the shape and size of the peanut kernels, from which properties such as surface area and volume can be determined [2,3]. Also, the design of the storage structures is related to the angle of repose and coefficient of friction of the peanuts [3,4]. Storage capacity and transportation depend on the bulk density of the peanut kernels; while the resistance to air flow essential parameter in the operations of aeration and drying are governed by the porosity of the peanut kernels mass.

In addition, those parameters are useful in determining the efficiency of machines and operations, evaluating the final product are quality, and classifying and distinguishing between different varieties. These results lead to a reduction in work efficiency and an increase in product loss. Therefore, the determination and consideration of these properties have important roles [5].

Ongoing through the literature, it is observed that in past very little research work carried out on physical properties of peanut varieties cv. GG-20 and TG-37A. Therefore, the present investigation was undertaken with the objectives to determine the physical properties of GG-20 and TG-37A peanut kernels, which are very popular in Saurashtra region of Gujarat which may be useful for new machinery design and development.

\section{Materials and Methods}

Materials

Healthy and mature Seed of Groundnuts variety GG-20 and TG37A, popular in Saurashtra region were brought from Main Oilseed Station (Groundnut), Junagadh Agricultural University; Junagadh (Gujarat). 


\section{Methods}

\section{Size}

A digital screw gauge (make - Mittutoyo, capacity - 0 to 300 $\mathrm{mm}$, accuracy $-0.01 \mathrm{~mm}$ ) was used for the measurement of length, width and thickness. All the dimensions were measured for randomly selected 100 peanut kernels and the average values of length (mm), width ( $\mathrm{mm}$ ) and thickness (mm) were noted (Mohsenin, 1986).

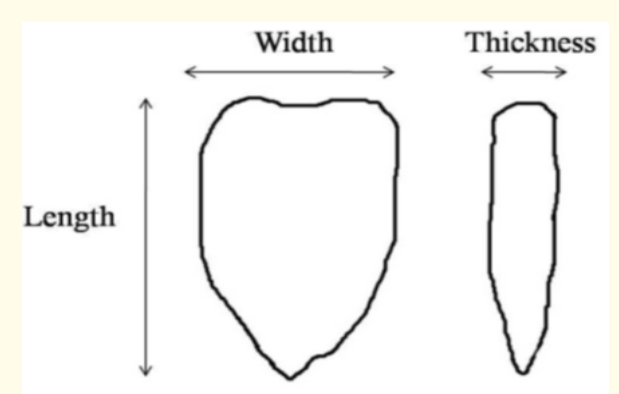

Figure 1: Characteristic dimensions of reference seed.

\section{Shape}

The shapes of 20 kernels of peanut kernels were decided using charted standard method. The longitudinal and lateral cross section of the peanut kernels were traced and compared with the shape listed on a Chartered Standard given by Mohsenin [6].

\section{Moisture content}

Moisture content of peanut kernels was determined using oven drying method [7]. The sample was dried in hot air oven at $105^{\circ} \mathrm{C}$ for $5 \mathrm{~h}$ or till the constant weight achieved. After drying, the sample was taken out and then cooled in desiccator and weighed after the sample attained room temperature. The data were recorded and the moisture content was calculated using the following formula;

Moisture Content (wb),\%= $\frac{\mathrm{Wm}}{\mathrm{Wd}} \times 100$

Where,

$\mathrm{Wm}=$ mass of water removed, $\mathrm{g}$

$\mathrm{Wd}=$ mass of dry matter, $\mathrm{g}$

\section{Hundred kernels weight}

The 100 kernels weight was measured by taking the weight of 100 kernels of peanut kernels in triplicate using digital weighing balance (make - Mettler Toledo (MS105), max - 120g, d - $0.01 \mathrm{mg}$ ) and the average value was recorded [6].

\section{Geometric mean diameter}

The geometric mean diameter (Dg) of peanut kernels was determined from various dimensions and calculated as per the following relationship (Fashina., et al. 2014).

$\operatorname{Dg}(\mathrm{mm})=[(\mathrm{LWT})]^{1 / 3} \quad---\cdot-(2)$

Where,

L, W and T - Average value of Length, Width and Thickness, mm

\section{Aspect ratio}

The aspect ratio ( $\mathrm{Ra}$ ) is the ratio of the width to its respective length. The aspect ratio was calculated by applying the following relationship (Maduako and Faborode, 1990).

$\operatorname{Ra}(\%)=(\mathrm{W} / \mathrm{L}) \times 100$

Where,

$\mathrm{W}=$ Average Width, $\mathrm{mm}$

$\mathrm{L}=$ Average Length, $\mathrm{mm}$.

\section{Sphericity}

The sphericity is the ratio of geometric mean diameter to the length of seed. The sphericity of 100 peanut kernels was calculated by using the following relationship [8].

Sphericity=Dg/L

Where,

$\mathrm{Dg}=$ Geometric mean diameter, $\mathrm{mm}$

$\mathrm{L}=$ Length, $\mathrm{mm}$.

\section{Surface area}

The surface area of peanut kernels s was found as per equation given below (Moshenin, 1986). The geometric mean diameter was calculated from equation 3.2 .

$\mathrm{S}\left(\mathrm{mm}^{2}\right)=\pi \mathrm{Dg}^{2} \quad---(5)$

Where,

$\mathrm{S}=$ Surface area, $\mathrm{mm}^{2}$

$\mathrm{Dg}=$ Geometric mean diameter, $\mathrm{mm}$

\section{Bulk density}

Bulk density was determined by measuring the weight of peanut kernels of known volume. The sample was placed in a container of regular shape and the excess on the top of the container was removed by sliding a string or stick along the top edge of the container. After the excess removed completely, the weight of the sample was measured. The bulk density of the sample was obtained simply by dividing the weight of the sample by the volume of container [9]. The observations were replicated for 4 times to verify the results.

B. D. $\left(\mathrm{kg} / \mathrm{m}^{3}\right)=$ Weight of sample/Volume of the container ------ (6)

\section{True density}

True density was determined using Toluene Displacement Method (TDM). The volume of toluene displaced was observed by immersing a weighed quantity of peanut in the toluene. The true density was calculated by using following equation [9]. The observations were replicated for 3 times to verify the results.

T. D. $\left(\mathrm{kg} / \mathrm{m}^{3}\right)$ = Weight of sample/True volume ------ (7)

\section{Porosity}

Porosity is defined as that fraction of space in the bulk grain that is not occupied by the grain. The percentage fractional porosity was evaluated from the following relation [9].

Porosity $(\%)=(1-$ Bulk density/True density $) \times 100$----- $(8)$ 


\section{Terminal velocity}

The terminal velocities of seed at different moisture contents were measured using a cylindrical air column in which the material was suspended in the air stream (Joshi., et al. 1993; Baryeh, 2002; Yalçın, 2007). Relative opening of a regulating valve provided at blower output end was used to control the airflow rate. In the beginning, the blower output was set at minimum. For each experiment, a sample was dropped into the air stream from the top of the air column. Then airflow rate was gradually increased till the seed mass gets suspended in the air stream. The air velocity which kept the seed suspension was recorded by a digital anemometer (Thiesclima, Germany) having a least count of $0.1 \mathrm{~m} / \mathrm{s}$.

\section{Angle of repose}

The emptying or dynamic angle of repose was determined using a box provided with removable sliding door. The box was filled with the peanut kernels and then the bottom sliding door was quickly removed, allowing the kernels to form a heap. The height of the cone was measured and the filling angle of repose $(\theta)$ was calculated by the following relationship.

$\theta=\tan -1(2 \mathrm{H} / \mathrm{D})$----- (9)

Where,

$\mathrm{H}$ and $\mathrm{D}$ are the height and diameter of the cone $(\mathrm{cm})$ respectively

\section{Coefficients of friction}

The static coefficient of friction for peanut kernels was determined with respect to three different surfaces such as glass, wood and aluminium. A known mass of the samples was filled in a cylinder and with the cylinder resting on the surface, it was raised gradually until the filled cylinder just started to slide down [10]. The co-efficient of friction $(\mu)$ was calculated by using the following equations,

$\mu=\tan \varnothing$----- (10)

Where $\varnothing$ is the angle of tilt.

\section{Germination percent}

Seed germination was determined by the wet paper method [11]. Thirty kernels in four replicates were placed in moistened germination paper. These were finally wrapped in a sheet of wax paper to reduce surface evaporation and placed in a germination incubator at $25^{\circ} \mathrm{C}$ in an upright position in a suitable container. Germination percentage was recorded after 7 days on the basis of the normal seedlings only.

Germination $(\%)=\frac{\text { Number of germinated kernels } \times 100}{\text { Total number of kernels }}$

\section{Results and Discussion}

A random sample of about 100 kernels was taken from each variety to obtain data about some physical properties such as, size, shape, sphericity, 100 kernels weight, geometric mean diameter, surface area, aspect ratio, true density, bulk density and porosity peanut seed cv. GG-20 and TG-37A.

\begin{tabular}{|l|c|c|}
\hline \multicolumn{1}{|c|}{ Physical Properties } & GG-20 & TG-37A \\
\hline Moisture content, \% (w.b) & $6.0 \pm 0.78$ & $6.5 \pm 1.08$ \\
\hline Length (mm) & $14.53 \pm 1.99$ & $11.37 \pm 1.20$ \\
\hline Width (mm) & $8.73 \pm 0.54$ & $7.90 \pm 1.18$ \\
\hline Thickness (mm) & $7.87 \pm 0.47$ & $7.17 \pm 1.04$ \\
\hline Shape & Oblong & Oblate \\
\hline Sphericity (mm) & $0.72 \pm 0.06$ & $0.78 \pm 0.06$ \\
\hline 100 kernels weight (mm) & $56.40 \pm 1.69$ & $37.04 \pm 1.79$ \\
\hline Geometric mean diameter & $10.38 \pm 0.76$ & $8.81 \pm 0.95$ \\
(mm) & $343.37 \pm 57.81$ & $246.64 \pm 50.89$ \\
\hline Surface area (mm $\left.{ }^{2}\right)$ & $60.07 \pm 9.09$ & $69.47 \pm 10.55$ \\
\hline Aspect ratio $(\%)$ & $1003 \pm 10.77$ & $1170 \pm 6.30 \mathrm{~kg} / \mathrm{m}^{3}$ \\
\hline True density $\left(\mathrm{kg} / \mathrm{m}^{3}\right)$ & $606 \pm 5.15$ & $670 \pm 4.50 \mathrm{~kg} / \mathrm{m}^{3}$ \\
\hline Bulk density $\left(\mathrm{kg} / \mathrm{m}^{3}\right)$ & $39.58 \%$. & $42.74 \%$ \\
\hline Porosity $(\%)$ & $26 \pm 1.06$ & $22 \pm 1.22$ \\
\hline Angle of repose, degree & $12.3 \pm 0.67$ & $11.2 \pm 1.34$ \\
\hline Terminal velocity, m/s & \multicolumn{2}{|c|}{} \\
\hline Coefficient of friction & $0.36 \pm 0.03$ & $0.30 \pm 0.025$ \\
\hline Wood & $0.32 \pm 0.026$ & $0.26 \pm 0.015$ \\
\hline Glass & $0.34 \pm 0.019$ & $0.27 \pm 0.013$ \\
\hline GI & $81.30 \pm 1.26 \%$ & $84.80 \pm 1.56 \%$ \\
\hline Germination percentage $\%$ & \multicolumn{2}{|c|}{} \\
\hline
\end{tabular}

Table 1: Physical properties of GG-20 and TG-37 peanut kernels (Mean \pm S.D).

Size

The data on the three axial dimensions viz.; length, width and thickness of the GG-20 and TG-37A peanut kernels are reported (Table 2). A. The length of the peanut kernels varied from19.49 to $9.33 \mathrm{~mm}$ and 13.97 to 7.61 while the width ranges from 10.19 to 7.19 and 10.75 to $4.11 \mathrm{~mm}$ of GG-20 and TG-37A peanut kernels respectively. The thickness of GG-20 and TG-37A peanut kernels diverse. 100 peanut kernels of GG-20 and TG-37A were measured and the average dimensions of the kernels i.e. length, width and thickness were found to be $14.53 \pm 1.99 \mathrm{~mm}, 8.73 \pm 0.54 \mathrm{~mm}, 7.87$ $\pm 0.47 \mathrm{~mm}$ and $11.37 \pm 1.20 \mathrm{~mm}, 7.90 \pm 1.18 \mathrm{~mm}$ and $7.17 \pm 1.04$ $\mathrm{mm}$, respectively (Table 2). Similar observations have also been reported by Khorajiya and Akbari [12] for GG-20 peanut kernels.

\begin{tabular}{|l|c|c|c|c|c|}
\hline $\begin{array}{c}\text { Peanut } \\
\text { Variety }\end{array}$ & Parameters & $\begin{array}{c}\text { Average } \\
\text { Value }\end{array}$ & SD & CV & Range \\
\hline \multirow{4}{*}{ GG-20 } & Length (mm) & 14.53 & 1.99 & 13.71 & $19.49-9.33$ \\
\cline { 2 - 6 } & Width (mm) & 8.73 & 0.54 & 6.22 & $10.19-7.19$ \\
\cline { 2 - 6 } & $\begin{array}{c}\text { Thickness } \\
\text { (mm) }\end{array}$ & 7.87 & 0.47 & 5.93 & $9.16-6.87$ \\
\hline \multirow{4}{*}{ TG-37A } & Length (mm) & 11.37 & 1.20 & 10.56 & $13.97-7.61$ \\
\cline { 2 - 6 } & Width (mm) & 7.90 & 1.18 & 14.91 & $10.75-4.11$ \\
\cline { 2 - 6 } & $\begin{array}{c}\text { Thickness } \\
\text { (mm) }\end{array}$ & 7.17 & 1.04 & 14.54 & $9.45-3.33$ \\
\hline
\end{tabular}

Table 2: Three axial dimensions of peanut kernels. 


\section{Shape}

The shape of GG-20 and TG-37A peanut kernels was found using Chartered Standard (Table 2). The shape of GG-20 was noted oblong whereas it reported oblate for TG-37A peanut seed.

\section{Sphericity}

Sphericity of grain signifies the ability of grain to roll rather than slide in grain hopper, feeding drum, delivery tube etc. Hence, higher value of sphericity, more ability of grain to roll which is important attribute for designing grain hopper and grain conveying equipment. The value of sphericity of 100s kernels of GG-20 and TG-37A were calculated and reported Table 1 . The average value of sphericity of GG-20 and TG-37A peanut kernels was found to be $0.72 \pm 0.06$ and $0.78 \pm 0.06$ respectively

\section{0 kernels weight}

It was measured directly by taking the weight of 100 kernels of peanut by digital weighing balance. The experiment was replicated thrice and the average weight of 100 kernels. The 100 kernels weight ofGG-20 and TG-37A was found to be $56.40 \pm 1.69 \mathrm{~g}$ and $37.04 \pm 1.79$ respectively.

\section{Geometric mean diameter}

The Geometric mean diameter of GG-20 and TG-37A kernels were found to be $10.38 \pm 0.76 \mathrm{~mm}$ and $8.81 \pm 0.95 \mathrm{~mm}$, respectively.

\section{Surface area}

The surface area of 100peanut kernels was found using formula given by Moshenin (1986) and the average value of Surface area for GG-20 and TG-37A peanut kernels were obtained $343.37 \pm 57.81$ and $246.64 \pm 50.89 \mathrm{~mm}^{2}$ respectively and noted in Table 1 .

\section{Aspect ratio}

The average value of Aspect ratio for GG-20 and TG-37A peanut kernels found to be $60.07 \pm 9.09$ and $69.47 \pm 10.56 \%$ respectively, as reported in Table 1

\section{True density, bulk density and porosity}

True density and bulk density of GG-20 peanut kernels were determined and verified by repeating the same procedure for 5 times and found to be $1003 \pm 10.77 \mathrm{~kg} / \mathrm{m}^{3}$ and $606 \pm 5.15 \mathrm{~kg} / \mathrm{m}^{3}$, respectively. Average value of porosity was found to be $39.58 \%$. The True density and bulk density of TG-37A peanut kernels were measured to be $1170 \pm 6.30 \mathrm{~kg} / \mathrm{m}^{3}$ and $670 \pm 4.50 \mathrm{~kg} / \mathrm{m}^{3}$, respectively. Average value of porosity was found to be $42.74 \%$.

\section{Terminal Velocity}

The terminal velocity of peanut varieties used in the study is shown in table 1 . The average terminal velocity GG-20 and TG-37A peanut kernels found to be $12.3 \pm 0.67$ and $11.2 \pm 1.34 \mathrm{~m} / \mathrm{s}$ respectively.

\section{Angle of repose}

Angle of repose depicts the maximum angle at which heap of loose solids will stand without sliding. The angle of repose determines the maximum angle of a pile of peanut in the horizontal plane. It is important in the filling of a flat storage facility when grain is not piled at a uniform bed depth but is peaked (Mohs- enin, 1986). Additionally, it is beneficial for designing equipment for mass flow, storage structure and determining the contour of a pile. The average value of Angle of repose for GG-20 and TG-37A peanut kernels found to $26 \pm 1.060$ and $22 \pm 1.220$ respectively, as reported in table 1.

\section{Coefficients of friction}

The coefficients of friction for peanut kernels were determined with respect to wooden, glass and G.I sheet metal surfaces are presented in Table 2.Coefficients of friction were greatest for wooden and least for glass surface was found for both the samples. Coefficients of friction of GG-20 peanut kernels were determined and verified by repeating the same procedure for three times and found to be $0.36 \pm 0.03,0.32 \pm 0.026$ and $0.34 \pm 0.019$ for wooden, glass and G.I metal sheet surfaces respectively. Coefficients of friction of TG-37A peanut kernels were determined and also verified by repeating the same procedure for three times and found to be 0.30 $\pm 0.025,0.26 \pm 0.015$ and $0.27 \pm 0.013$ for wooden, glass and G.I metal sheet surfaces respectively.

\section{Germination percent}

The Germination percent of peanut kernels was found using Seed germination was determined by the wet paper method (ISTA, 1985). The average value of Germination percent for GG-20 and TG-37A peanut kernels were obtained $81.30 \pm 1.26 \%$ and $84.80 \pm$ $1.56 \%$ respectively and noted in table 1 .

\section{Distribution of kernels}

The per cent distribution of different dimension i.e. Length, Width and Thickness of peanut variety cv. GG-20 and TG-37A seed is shown in table 3.

Table 3 show the Length, width and thickness distribution of GG-20 peanut kernels at $6.0 \pm 0.78$ moisture Content. From the Figure 1 it can be seen that the maximum, 39\% per cent peanut kernels length fall in the length range of 13.33-15.32 mm followed by the range 15.33 - $17.32 \mathrm{~mm}$ with $24 \%$ peanut kernels length. Only the 5\% peanut kernels length was observed in $9.33-11.32$ range. In case of Width distribution of GG-20 peanut kernels, the $71 \%$ per cent peanut kernels width distribution fall in the length range of $8.20-9.19 \mathrm{~mm}$ followed by the range $7.20-8.19 \mathrm{~mm}$ and $9.20-10.19 \mathrm{~mm}$ with $14 \%$ peanut kernels width distribution. Only the $1 \%$ peanut kernels width was noted in $6.20-7.19 \mathrm{~mm}$ range. The Thickness of GG-20 peanut kernels was observed $50 \%$ in range of $13.33-15.32 \mathrm{~mm}$ followed by the range $7.87-8.86 \mathrm{~mm}$ with $45 \%$ seed Thickness distribution. Only the $1 \%$ seed Thickness was observed in 5.87-6.86 $\mathrm{mm}$ range.

\section{TG-37A seed distribution}

The percent distribution of different dimension i.e. Length, Width and Thickness of TG-37A at $6.5 \pm 1.08 \%$ moisture content of peanut seed is shown in table 3 . The maximum $52 \%$ seed Length distribution fall in range of 10.62 - $12.11 \mathrm{~mm}$ followed by the range 9.12 - $10.61 \mathrm{~mm}$ with $22 \%$ seed Length distribution was observed. Only the $3 \%$ seed length was observed in $7.60-9.11 \mathrm{~mm}$ range. Whereas the width scattering of TG-37A peanut kernels at $6.5 \pm$ 1.08 moisture Content found maximum $47 \%$ in the length range of $7.12-8.61 \mathrm{~mm}$. The $29 \%$ peanut kernels width fall in range of 


\begin{tabular}{|c|c|c|c|c|}
\hline $\begin{array}{l}\text { Sr. } \\
\text { No. }\end{array}$ & $\begin{array}{l}\text { Peanut } \\
\text { Variety }\end{array}$ & Dimension & Range, mm & $\begin{array}{c}\text { Kernels } \\
\text { Percentage }\end{array}$ \\
\hline \multirow{13}{*}{1} & \multirow[t]{13}{*}{ GG -20} & \multirow[t]{5}{*}{ Length } & $9.33-11.32$ & 5 \\
\hline & & & $11.33-13.32$ & 22 \\
\hline & & & $13.33-15.32$ & 39 \\
\hline & & & $15.33-17.32$ & 24 \\
\hline & & & $17.33-19.49$ & 10 \\
\hline & & \multirow[t]{4}{*}{ Width } & $6.20-7.19$ & 1 \\
\hline & & & $7.20-8.19$ & 14 \\
\hline & & & $8.20-9.19$ & 71 \\
\hline & & & $9.20-10.19$ & 14 \\
\hline & & \multirow[t]{4}{*}{ Thickness } & $5.87-6.86$ & 1 \\
\hline & & & $6.87-7.86$ & 50 \\
\hline & & & $7.87-8.86$ & 45 \\
\hline & & & $8.87-9.86$ & 4 \\
\hline \multirow[t]{14}{*}{2} & \multirow[t]{14}{*}{$\mathrm{TG}-37 \mathrm{~A}$} & \multirow[t]{5}{*}{ Length } & $7.60-9.11$ & 3 \\
\hline & & & $9.12-10.61$ & 22 \\
\hline & & & $10.62-12.11$ & 52 \\
\hline & & & $12.12-13.61$ & 18 \\
\hline & & & $13.62-15.11$ & 5 \\
\hline & & \multirow[t]{5}{*}{ Width } & $4.10-5.61$ & 4 \\
\hline & & & $5.62-7.11$ & 19 \\
\hline & & & $7.12-8.61$ & 47 \\
\hline & & & $8.62-10.11$ & 29 \\
\hline & & & $10.13-11.61$ & 1 \\
\hline & & \multirow[t]{4}{*}{ Thickness } & $4.32-5.83$ & 3 \\
\hline & & & $5.84-7.33$ & 17 \\
\hline & & & $7.34-8.83$ & 50 \\
\hline & & & $8.84-10.33$ & 29 \\
\hline
\end{tabular}

Table 3: Distribution of peanut kernels.

\section{Conclusion}

The physical properties of the peanut seed varieties namely, GG20 and TG-37A were investigated in this study. It is evident from the study GG-20 that is larger in size, weight, Geometric mean diameter, Angle of repose, Terminal velocity, Coefficient of friction (Wood, Glass, GI Surface); whereas it exhibits less bulk density, true density and porosity, Aspect ratio and Germination percentage in contrast to TG-37A. As equipment design crucially depends on the physical and engineering properties of peanut seed for easy; efficient, proper and economical equipment design, hence the studied varieties would be explored with greater ease.

\section{Bibliography}

1. Hymowitz T. “Grain legumes”. In: Janick, J. and Simon, J. E. (ed.), Advances in new crops. Timber Press, Portland, OR (1990): 54-57.

2. Kachru Y. "Monolingual bias in SLA research". TESOL Quarterly 28.4 (1994): 795-800.

3. Sologubik CA., et al. "Effect of moisture content on some physical properties of barley". Industrial Crops and Products 43 (2013): 762-767.
4. Vilche, C., et al. "Physical properties of quinoa kernels". Biosystems Engineering 86.1 (2003): 59-65.

5. Fathollahzadeh B., et al. "Antimicrobial susceptibility patterns and distribution of blaOXA genes among Acinetobacter spp. Isolated from patients at Tehran hospitals". Japanese Journal of Infectious Diseases 61.4 (2008): 274-278.

6. Mohsenin NN. Physical properties of plant and animal materials (No. 581.1 M64 1986) (1986).

7. AOAC. "Official Methods of Analysis". Association of Official Analytical Chemists. Washington, USA (2006).

8. Olajide JO and Igbeka JC. "Some physical properties of groundnut kernels". Journal of Food Engineering 58 (2018): 201-204.

9. Morita T and Singh RP. "Physical and thermal properties of short-grain rough rice". Transactions of the ASAE 22.3 (1979): 630-0636.

10. Varnamkhasti MG., et al. "Some physical properties of rough rice (Oryza Sativa L.) grain". Journal of Cereal Science 47 (2008): 496-501.

11. ISTA. "International rules for seed testing". Seed Science and Technology 13 (1985): 299-513.

12. Khorajiya RV and Akbari SH. "Standardization of process parameters for the development of partially defatted peanut, $\mathrm{M}$. Tech. Thesis (Unpublished)". Food Processing Technology, AAU, Anand (2016).

13. Anonymous. Production, Post-Harvest Losses. Ministry of Agriculture and Farmers Welfare, Directorate of Marketing and Inspection, Post Harvest Profile of Groundnut. Faridabad (2005): 2-7.

\section{Assets from publication with us}

- Prompt Acknowledgement after receiving the article

- Thorough Double blinded peer review

- Rapid Publication

- Issue of Publication Certificate

- High visibility of your Published work

Website: www.actascientific.com/

Submit Article: www.actascientific.com/submission.php Email us: editor@actascientific.com Contact us: +919182824667 